\title{
Complex evaluation of the modern atmospheric air of city ecosystems
}

\author{
Galina Ulivanova ${ }^{1}$, Olga Fedosova $^{1, *}$, and Olga Antoshina ${ }^{2}$ \\ ${ }^{1}$ Ryazan State Agrotechnological University named after P.A. Kostychev, Department of Animal Science and Biology, 390044 Ryazan, \\ Russia \\ ${ }^{2}$ Ryazan State Agrotechnological University named after P.A. Kostychev, Department of Forestry, Agrochemistry and Ecology, 390044 \\ Ryazan, Russia
}

\begin{abstract}
The results of studies of the chemical composition of atmospheric air showed that the concentration of ammonia $\left(0.2520 \mathrm{mg} / \mathrm{m}^{3}\right)$, nitrogen dioxide $\left(0.3942 \mathrm{mg} / \mathrm{m}^{3}\right)$ and hydrogen sulfide $\left(0.0269 \mathrm{mg} / \mathrm{m}^{3}\right)$ exceeded the MPC requirements. The seasonal dynamics of the spread of aerogenic pollutants revealed a decrease in $\mathrm{NO}, \mathrm{NO}_{2}, \mathrm{H}_{2} \mathrm{~S}, \mathrm{SO}_{2}$ from winter to the spring-summer season. However, the content of such pollutants as $\mathrm{NH}_{3}, \mathrm{CO}$ and dust increased significantly in summer to $0.0816,3.7140$ and $0.0289 \mathrm{mg} / \mathrm{m}^{3}$ respectively. During bio-indication of 363 trees only 4 species of the 16 studied ones were characterized as healthy $(\mathrm{K}<1.5)$. The overall level of attenuation was 2.16 ("weakened forest"). Evaluation of the fluctuating asymmetry showed high resistance of the maple (Acer Platanoides) to environmental pollution (the level of asymmetry in the transport zone was 0.039 against $0.077-0.078$ in the silver birch (Betula pendula) and the fragrant poplar (Populus suaveolens). The high level of anthropogenic pollution in the transport zones of the city adversely affected roadside biotopes. It has been proven that roadside phytocenosis is significantly sparse and the population density drops sharply by $50-100 \%$, compared to cleaner functional areas. The results of lichenoid indication showed that in most of the sites studied, the air was highly polluted (pollution class 1 ) and the concentration of $\mathrm{S}_{2}$ was $0.10-0.30 \mathrm{mg} / \mathrm{m}^{3}$.
\end{abstract}

\section{Introduction}

The complex, contradictory, aggravated with each passing year problems of the relationship of humanity with nature are at the epicenter of the attention of many scientists, public figures and even ordinary people who want to live in a safe and comfortable world.

The growing danger of the negative impact of industrial and agricultural production on human health and on the state of the biosphere as a whole has led to the creation of warning systems, monitoring and forecasting the state of both individual environmental objects and the entire biosphere. Such an information system to observe and analyze the state of the natural environment, primarily the control of pollution levels and the effects it causes in the biosphere, is called monitoring.

One of the most important objects of the environment is atmospheric air. The problem of air pollution became particularly acute in the second half of the twentieth century, characterized by extremely high rates of growth in industrial production, production and consumption of electricity, production and use of a large number of vehicles. As a result, changes in the gas composition of the atmosphere were noted: an increase in the concentration of some components and the appearance of new pollutants in it.
On the basis of data on emissions of pollutants into the atmosphere published in recent years, every seventh or eighth Russian city is in a difficult ecological situation [1-6].

The complex of environmental problems is quite extensive in Ryazan, as in any industrially developed city. Thus, according to State Report "On the state of sanitary and epidemiological well-being of the population in Ryazan region in 2017", the share of air samples exceeding the maximum permissible concentrations was $0.5 \%$. The proportion of nonstandard water samples from the Oka River, a surface source of water supply, was $12.5 \%$ according to sanitary and chemical parameters and $13.3 \%$ microbiological parameters; the share of soil samples that did not meet standards for sanitary and hygienic parameters was 2.6 $\%$; for microbiological parameters it was $7.5 \%$.

According to Ryazan administration, the main share of pollutants emitted into the air from stationary sources is still represented by volatile and nonvolatile organic compounds $(48.9 \%)$, sulfur dioxide $(24.5 \%)$, nitrogen oxides (dioxide nitrogen) (14.5\%) and carbon monoxide $(9.5 \%)[3,4,6,7]$.

Thus, due to the increasing urgency of environmental problems and the need to take decisive and justified measures to improve the environmental situation, it is necessary to conduct comprehensive monitoring studies

* Corresponding author: fedosowa1986@mail.ru 
of the state of anthropo-ecosystems. Therefore, the purpose of investigations was the integrated monitoring of the current state of atmospheric air in the city of Ryazan and the evaluation of its impact on urban ecosystems.

\section{Objects and methods}

Experimental studies were conducted in various functional areas of the city: transport, residential, social, business and recreational in 2018, according to a set of techniques: physical and chemical analysis, bioindication [8-10].

The first stage included the following:

1) evaluation of the intensity of the traffic flow according to GOST - 17.2.2.03-87 (recording was carried out three times a day: in the morning (7-8 h), in the afternoon (13-14 h) and in the evening (17-18 h);

2) calculation of emissions of moving vehicles in accordance with the methodological guidelines for the inventory of emissions of pollutants into the atmosphere for road transport enterprises (by the calculation method) $[11,12]$.

The second stage consisted in determining air pollutants in the city of Ryazan using gas analyzer "SV320-A2", gas analyzer "K-100", atomic absorption spectrometer "KVANT-AFA" and combined automatic dust meter "OMPN-10.0". The studies took place in districts (Soviet, Railway, Moscow and October) and took into account the season.

The third stage included:

1) evaluation of the state of the forest using the simplest scale (16 tree species) and the study of the fluctuating asymmetry of forest cover (the studied species are the silver birch (Betula pendula), the maple (Acer Platanoides) and the fragrant poplar (Populus suaveolens)) using standard techniques;

2) evaluation of morphometric parameters of flowering plants common dandelion (Taraxacum officinale) and common plantain (Plantago major);

3) evaluation of air pollution by lichen indication: determining the average degree of lichen coverage, biotic index and poly-tolerance index (the studied trees are representatives of the silver birch (Betula pendula) and the black poplar (Populus nigra)).

\section{Estimation of the traffic flow and calculation of emissions of the moving vehicles}

The main source of aerogenic pollution in the modern city is undoubtedly road transport, whose share in the overall structure of urban pollution is steadily increasing.

According to the results of monitoring the intensity of traffic on roads and motorways of Ryazan, it was found that most of them had typical traffic intensity (according to GOST - 17.2.2.03-87). The total traffic on the streets was 7-17 thousand vehicles per day. It is especially necessary to note the main transport highways of the city - the North and South ring roads, the Moscow
Highway - the intensity of the traffic flow on which is characterized as high (18-27 thousand vehicles).

A comparative analysis of daily dynamics shows an increase in traffic flow in the morning and evening by an average of $25 \%$ compared with daytime hours. Passenger cars accounted for $73.41 \%$, buses $-4.14 \%$ and trucks $-22.14 \%$. All this leads to an increase in emissions. Thus, the calculations showed that the total amount of emitted carbon monoxide, which is the main indicator of air pollution by motor vehicle emissions on roads passing through the Southern District of the Railway district, increased from 23.1 to $38.5 \mathrm{mg} / \mathrm{m}^{3}$ or $82.4 \%$. The situation is no better in other areas of the city.

Recent studies conducted in the Moscow district of Ryazan in 2018 (Krupskaya Street, Novatorov Street, Velikanov Street (Narodny Boulevard)) made possible to calculate the running exhaust emissions of vehicles according to standard methods [13]. The calculations showed a significant excess of the concentration of pollutants such as carbon monoxide (CO), nitrogen oxides $\left(\mathrm{NO}_{\mathrm{x}}\right)$ in terms of nitrogen dioxide $\left(\mathrm{NO}_{2}\right)$, as well as lead compounds.

The concentration of carbon monoxide had the greatest excess over MPC d.a. (calculated concentrations were 23-72 MPC).

A large enough excess (12-51 MPC) was obtained for total nitrogen oxides, usually converted to nitrogen dioxide, which is the most dangerous pollutant in this group. The estimated excess of lead compounds over MPC d. a. amounted to 1.63-6.8 times, which is also quite dangerous for the environment and humans, since lead and its compounds belong to hazard class 1 .

When comparing the calculated concentrations with another standard - MPC o.t. - the excess was detected only by two parameters: carbon monoxide and aggregates of nitrogen oxides (by 7.6-24.1 and 1.1-2.4 MPC, respectively). Moreover, the excess concentration of nitrogen oxides was not noted in all cases (Figure 1).

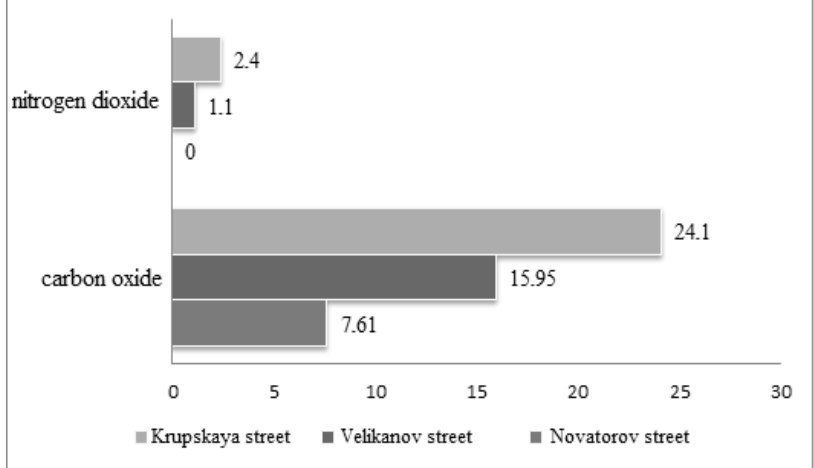

Fig. 1. The level of the excess of the estimated pollution parameters over MPC o. t.

\section{The study of the chemical composition of atmospheric air}

The results of studies of the chemical composition of atmospheric air in Ryazan showed an excess of MPC for such parameters as ammonia $\left(0.2520 \mathrm{mg} / \mathrm{m}^{3}\right)$, nitrogen 
dioxide $\left(0.3942 \mathrm{mg} / \mathrm{m}^{3}\right)$ and hydrogen sulfide $(0.0269$ $\mathrm{mg} / \mathrm{m}^{3}$ ) (Table 1).

According to the data of Federal Budgetary Educational Institution of Health «The Center for Hygiene and Epidemiology in Ryazan Region», more than 6,000 samples of atmospheric air were investigated in Ryazan in 2018. Less than $1 \%$ of them exceeded the maximum permissible concentrations. The priority air pollutants were nitrogen dioxide, hydroxybenzene, formaldehyde, suspended solids, carbon oxide and ammonia.

Analysis of the study of atmospheric air in Ryazan showed that the NO concentration in the Soviet District was $0.0017 \mathrm{mg} / \mathrm{m}^{3}$, Railway $-0.0873 \mathrm{mg} / \mathrm{m}^{3}$, Moscow $0.0007 \mathrm{mg} / \mathrm{m}^{3}$ and October $-0.0168 \mathrm{mg} / \mathrm{m}^{3}$.

$\mathrm{NO}_{2}$ studies have shown that the highest content of this parameter is noted in the October $\left(0.0770 \mathrm{mg} / \mathrm{m}^{3}\right)$ and Soviet districts $\left(0.0782 \mathrm{mg} / \mathrm{m}^{3}\right)$, and in the Railway and Moscow districts their content was $0,0167 \mathrm{mg} / \mathrm{m}^{3}$ and $0.016 \mathrm{mg} / \mathrm{m}^{3}$, respectively.

The content of $\mathrm{NH}_{3}$ in the atmospheric air in the Soviet, Railway and October districts was $0.0254 \mathrm{mg} / \mathrm{m}^{3}$, $0.0477 \mathrm{mg} / \mathrm{m}^{3}$ and $0.2819 \mathrm{mg} / \mathrm{m}^{3}$, respectively.

Table 1. The results of the study of the content of pollutants in the atmospheric air of Ryazan in 2018

\begin{tabular}{|c|c|c|}
\hline Pollutant & $\begin{array}{c}\text { Concentration of } \\
\text { pollutants in the air, } \\
\mathrm{mg} / \mathrm{m}^{3}\end{array}$ & MPC, $\mathrm{mg} / \mathrm{m}^{3}$ \\
\hline $\mathrm{NO}$ & 0.0144 & 0.4000 \\
\hline $\mathrm{NO}_{2}$ & 0.3942 & 0.2000 \\
\hline $\mathrm{NH}_{3}$ & 0.2520 & 0.2000 \\
\hline $\mathrm{H}_{2} \mathrm{~S}$ & 0.0269 & 0.0080 \\
\hline $\mathrm{SO}_{2}$ & 0.0066 & 0.5000 \\
\hline $\mathrm{CO}$ & 0.3039 & 5.0000 \\
\hline Dust & 0.0402 & 0.5000 \\
\hline
\end{tabular}

The results of $\mathrm{H}_{2} \mathrm{~S}$ studies in the atmospheric air of Ryazan made possible to establish that the concentration of this parameter in the October district was 0.0064 $\mathrm{mg} / \mathrm{m}^{3}$, in the Railway district $-0.0018 \mathrm{mg} / \mathrm{m}^{3}$, in the Moscow district $-0.0013 \mathrm{mg} / \mathrm{m}^{3}$ and it was not identified in the Soviet district.

The content of $\mathrm{SO}_{2}$ in the atmospheric air in the Railway District corresponded to $0.0475 \mathrm{mg} / \mathrm{m}^{3}$, that in the Soviet district was $0.0005 \mathrm{mg} / \mathrm{m}^{3}$, that in the Moscow district was $0.0008 \mathrm{mg} / \mathrm{m}^{3}$ and that in the October district was $0.027 \mathrm{mg} / \mathrm{m}^{3}$.

The concentration of $\mathrm{CO}$ in the atmospheric air in the Soviet, Moscow and October districts was $0.3542 \mathrm{mg} / \mathrm{m}^{3}$, $0.2541 \mathrm{mg} / \mathrm{m}^{3}$ and $0.5217 \mathrm{mg} / \mathrm{m}^{3}$, respectively. At the same time, the highest $\mathrm{CO}$ content was observed in the Railway district and that was $2.9669 \mathrm{mg} / \mathrm{m}^{3}$.

Analysis of the results of the atmospheric air study in Ryazan showed that the dust content in the October District was $0.0567 \mathrm{mg} / \mathrm{m}^{3}$, Railway district $0.0298 \mathrm{mg} / \mathrm{m}^{3}$, Moscow district $-0.0064 \mathrm{mg} / \mathrm{m}^{3}$ and Soviet district $-0.0153 \mathrm{mg} / \mathrm{m}^{3}$.

The seasonal dynamics of the spread of aerogenic pollutants showed a decrease in $\mathrm{NO}, \mathrm{NO}_{2}, \mathrm{H}_{2} \mathrm{~S}, \mathrm{SO}_{2}$ and dust during the transition from winter to the springsummer season (Table 2). In the case of $\mathrm{NH}_{3}, \mathrm{CO}$ and dust there was a significant increase in concentration in summer. During the autumn period, the maximum permissible concentration for $\mathrm{H}_{2} \mathrm{~S}$ has been established.

Table 2. Results of the study of the content of pollutants in the atmospheric air of Ryazan in different seasons

\begin{tabular}{|c|c|c|c|c|c|}
\hline \multirow{2}{*}{$\begin{array}{l}\text { Pollut } \\
\text { ant }\end{array}$} & \multicolumn{4}{|c|}{ Concentration of pollutants, $\mathrm{mg} / \mathrm{m}^{3}$} & \multirow{2}{*}{$\begin{array}{l}\mathrm{MPC}, \\
\mathrm{mg} / \mathrm{m}^{3}\end{array}$} \\
\hline & winter & spring & summer & autumn & \\
\hline $\mathrm{NO}$ & 0.0773 & 0.0012 & 0.0016 & 0.0051 & 0.4000 \\
\hline $\mathrm{NO}_{2}$ & 0.0181 & 0.0140 & 0.0170 & 0.0199 & 0.2000 \\
\hline $\mathrm{NH}_{3}$ & 0.0030 & 0.0123 & 0.0816 & 0.0069 & 0.2000 \\
\hline $\mathrm{H}_{2} \mathrm{~S}$ & 0.0050 & 0.0002 & 0.0004 & 0.0159 & 0.0080 \\
\hline $\mathrm{SO}_{2}$ & 0.0029 & 0.0010 & 0.0013 & 0.0026 & 0.5000 \\
\hline $\mathrm{CO}$ & 0.6701 & 0.5102 & 3.7140 & 0.4496 & 5.0000 \\
\hline Dust & 0.0199 & 0.0179 & 0.0289 & 0.0636 & 0.5000 \\
\hline
\end{tabular}

In the course of the investigations it was revealed that the most polluted areas are the Railway and October districts, and the most common pollutants in these districts are $\mathrm{SO}_{2}, \mathrm{NH}_{3}$ and $\mathrm{CO}$.

The main pollutants of the air basin in the Ryazan region are Ryazan Oil Refining Company JSC, enterprises of the fuel and energy complex: Ryazanskaya GRES JSC, GRES-24, Novo-Ryazanskaya TPP, the branch of TGC-4 JSC Ryazan Regional Generation, enterprises producing building materials LLC Serebryansky Cement Plant, LLC Mikhailovsky Cement Plant and enterprises of Corporation Technonikol.

\section{Results of bio-indication and lichen indication}

Unfavorable features of the urban environment, and especially atmospheric pollution, significantly change the state of vegetation and affect both individual morpho-physiological parameters and the general condition of the plant, its longevity and adaptability.

Thus, with the accumulation of toxicants in tree species, the amount of nucleic acids in the leaves decreases, the exchange of nitrogenous compounds is disturbed, the intensity of transpiration and photosynthesis decreases, various deviations from bilateral symmetry appear, as well as the general weakening of the body, which is manifested in crown thinning, shortening of shoots, reduction of linear dimensions of leaves, etc. [14].

Studies of the effects of air pollution on the natural and cultural phytocenosis were carried out using a set of methods. The objects of the investigations were hardyshrub and herbaceous vegetation, as well as various types of lichens growing under urban ecosystems.

Studies conducted to analyze the degree of fluctuating asymmetry of tree species showed different degrees of sensitivity of species to the value of anthropogenic pressure of the environment. The objects of the study were such widespread in urban ecosystems species as the silver birch (Betula pendula), the maple 
(Acer Platanoides) and the fragrant poplar (Populus suaveolens).

A comparative analysis of the degree of resistance of these species showed that with a slight degree of pollution in the recreational areas of the city, the integral asymmetry index of the leaf of the studied species varies insignificantly (0.042-0.044), which confirms the fact that with a slight anthropogenic interference in the environment ("relatively pure" - 2 points on a standard scale) green planting retain their adaptive properties.

With an increase in the degree of anthropogenic pressure of the environment, differences appear in the level of adaptation of the studied species of woody vegetation. So in the residential area, characterized by a slightly higher level of anthropogenic pollution, the asymmetry of the silver birch leaf (Betula pendula) indicates significant deviations in the development (4 points on the standard scale), while the maple (Acer Platanoides) has only average deviation (3 points).

In the transport zone, these differences have become even clearer, so if for the silver birch (Betula pendula) and the fragrant poplar (Populus suaveolens) the ecological condition of the zone is critical and the influence of factors strongly affect the growth and development of trees (the asymmetry index was 0.077 and 0.078 , respectively), then for the maple (Acer Platanoides) the same habitat was more acceptable (Figure 2).

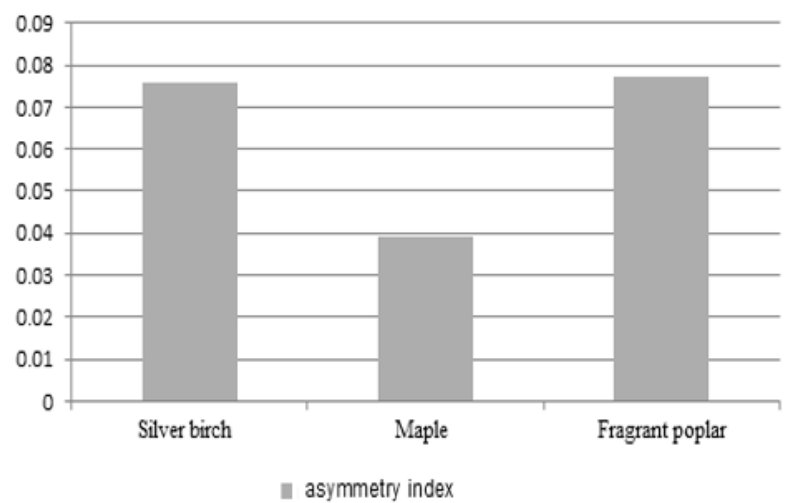

Fig. 2. Differences of fluctuating asymmetry of tree species in the transport zone

Thus, the silver birch (Betula pendula) and the fragrant poplar (Populus suaveolens) in these environmental conditions show less resistance to this type of anthropogenic interference. For them, the functional zone of the city, which is under constant pressure from chemical and physical factors caused by transport, is a habitat with ecological parameters that are critical for their existence.

Massive anthropogenic impact leads to general weakening of the city tree plantations, and reduces their adaptation to environmental conditions.

In various functional areas of the city, 363 trees belonging to 16 species were investigated, of which only 4 species were characterized as healthy $(K<1.5)$. These studies confirm the hypothesis that the maple trees are somewhat more resistant to anthropogenic effects on the environment. Thus, the level of the ash-leaved maple
(Acer negundo) trees status is characterized as "healthy" $(\mathrm{K}=1.40)$, and the maple species (Acer Platanoides), although being characterized as "weakened", has a relatively low level of attenuation compared to other species $(\mathrm{K}=1.99)$.

It is necessary to note the fact that cultivated plants have the least resistance to adverse factors. So, the evaluation of the state of apple tree plantings of different varieties showed the maximum level of attenuation compared with other types of the studied trees -2.81 . This does not contradict the studies of other scientists who have proved that the cultivated plants are less adapted than the natural biocenoses.

The danger of aerogenic pollution also lies in the fact that with air flows they can be transported long distances from the source of pollution, polluting other ecosystems, such as urban recreational zones.

Thus, studies conducted in the Lesopark zone, located near the Murom highway of the Soviet district of Ryazan, allowed to establish the presence of chemical burns, necrosis and chlorosis on the leaves of the trees in the park, although the Murom highway itself is characterized by relatively low traffic intensity (238 vehicles per hour). Similar results were obtained in the study of trees in the public garden of the Palace of Youth, which is located along Gagarin Street in the Railway District of Ryazan.

The main indicator species when evaluating the state of herbaceous vegetation were such widespread and relatively resistant to anthropogenic pollution species like the common dandelion (Taraxacum officinale) and the common plantain (Plantago major).

The high level of anthropogenic pollution in the transport zones of the city adversely affected roadside biotopes. It has been proved that roadside phytocenosis are largely sparse, the population density drops sharply (by 50-100\%) compared to cleaner functional areas, including residential ones, whose phytocenosis undergo trampling and periodic mowing. The plants of the transport zones are characterized by smaller linear sizes, both of shoots and leaves. So the length of the shoot of the common dandelion decreased by 3.5-7.7 \%, and that of the common plantain - by $50 \%$. The linear size of the leaves of this indicator plant also decreased by $31-50 \%$ compared with the recreational zone. Nevertheless, it turned out that the total number of leaves in plants of roadside biotopes increases by $18.3-24 \%$, respectively, for the common plantain and the common dandelion.

The greatest negative impact of environmental pollution has been on the total generative characteristics of plants, which leads to a decrease in reproductive qualities, reflected in a decrease in total seed productivity and deterioration in the quality of plant pollen. Thus, with an increase in the level of anthropogenic pressure on the environment in the transport zone of the city, the average weight of a single dandelion inflorescence decreased by $66.7 \%$, the total number of flowering shoots per $1 \mathrm{~m}^{3}-$ by $28.3 \%$, seed productivity - by $34.9 \%$ and the proportion of abortive pollen grains increased by $55 \%$. Similar studies with another indicator species (the common plantain) showed a sharp decrease in the number of flowering shoots - by 
$134.7 \%$ and seed productivity - by $94.6 \%$. Although the share of abortive pollen grains in this case has not increased so much - only by $20 \%$.

The calculations of the phytocenotic plasticity index (Ip) confirmed the conclusions about the greater sensitivity of the generative characteristics of indicator plants to the anthropogenic pressure of the medium (0.207-0.407 against $0.143-0.232$ for vegetative characteristics). When comparing the degree of sensitivity of the indicator species, it also turned out that the common plantain was more sensitive to the level of environmental comfort than the dandelion ( $\mathrm{I}=0.298$ and 0.194, respectively).

An anthropogenic change in the environment leads to a whole complex of unfavorable changes, including the appearance and increase in the number of morphological deviations in the development of vegetation. Thus, in roadside biotopes, the following negative moments were found: presence of necrotic changes and morphological deformation of the leaf blade in indicator species, early yellowing and wilting of plants, curvature and fasciation of flowering shoots ("double stems"), cleistogamy and decrease in the diameter of the generative shoot.

Lichens are one of the main objects of global biological monitoring, as they are widespread throughout the planet, and are hypersensitive to aerogenic pollution.

In the course of investigations, six species of lichens were discovered at seven experimental sites in Ryazan: Xanthoria parietina, Parmeliopsis ambigua, Lecanora allophana, Lecanora conizaeooides, Physcia aipolia and Parmelia sulcata. Analysis of the taxonomic affiliation of the species found showed that all lichens belong to the same class Lecanoromycetes, in three orders: Teloschistales, Caliciales and Lecanorales.

The average degree of tree trunks coverage with lichens at the experimental site Pervomaysky Prospect was $15.7 \%$, the air was very heavily polluted; that on the site of Gagarin Street was $18 \%$ and in the Central Park the air was relatively clean and the average degree of coverage was $50.6 \%$. The average degree of coverage at the experimental site of the urban forest in Nakhimov Street was $30.5 \%$, this area was moderately polluted. The air in Chernovitskaya Street was very polluted and the average degree of coverage was $8.2 \%$. The average coverage at the experimental site in Mussorgsky Street was $5 \%$. The air in Vokzalnaya Street was much polluted and the average degree of tree trunks coverage with lichens was $11.1 \%$.

According to the data obtained, four experimental sites belong to the first class of pollution - the biotic index ranged from 1.5 to 1.9 . The experimental site - the square, located on Gagarin Street, belongs to the second class of pollution (the biotic index is 2.03). The biotic index on the experimental site - the urban forest, located on Nakhimov Street is 4.15 , which indicates the third class of air quality. The experimental site of the Central Park of Culture and Leisure belongs to the fourth class of air quality (the biotic index is 5).

The calculation of the poly-tolerance index showed that the concentration of $\mathrm{SO}_{2}$ in the atmosphere for most experimental sites was $0.10-0.30 \mathrm{mg} / \mathrm{m}^{3}$. The atmospheric air in these areas was highly polluted. At site number 4, the urban forest on Nakhimov Street, the Southern District the poly-tolerance index was 7.61; the concentration of $\mathrm{S}_{2}$ in the atmosphere was $0.08-0.10$ $\mathrm{mg} / \mathrm{m}^{3}$, the territory is moderately polluted. The polytolerance index for the Central Park of Culture and Recreation showed that the concentration of $\mathrm{SO}_{2}$ in the atmosphere $=0.03-0.08 \mathrm{mg} / \mathrm{m}^{3}$ and the atmospheric air was relatively clean.

\section{Conclusion}

According to the results of monitoring the intensity of traffic on roads and motorways of Ryazan, it was found that most of them had typical traffic intensity of 7-17 thousand cars per day and it is worth mentioning the Northern and Southern ring roads, and Moscow highway with high intensity of motor transport (18-27 thousand). Passenger cars prevail in the flow structure $(73.41 \%)$. Calculations of the running emissions showed a significant excess over the MPC d. a. of carbon monoxide (23-72 MPC), a set of nitrogen oxides in terms of nitrogen dioxide (12-51 MPC), as well as lead compounds (1.63-6.8 MPC). When comparing the calculated concentrations with another standard - MPC o.t. - the excess was found only by two parameters: carbon monoxide and aggregates of nitrogen oxides (by 7.6-24.1 and 1.1-2.4 MPC, respectively).

A comprehensive analysis of the state of the atmospheric air in the city of Ryazan revealed the presence of an excess of MPC for such parameters as ammonia $\left(0.2520 \mathrm{mg} / \mathrm{m}^{3}\right)$, nitrogen dioxide $\left(0.3942 \mathrm{mg} / \mathrm{m}^{3}\right)$ and hydrogen sulfide $\left(0.0269 \mathrm{mg} / \mathrm{m}^{3}\right)$. During the transition from winter to the spring-summer season, a decrease in the concentration of most of the investigated substances was observed. However, it is necessary to note a significant increase in the concentration of $\mathrm{NH}_{3}, \mathrm{CO}$ and dust in the summer (up to $0.0816 \mathrm{mg} / \mathrm{m}^{3}, 3.7140$ and $0.0289 \mathrm{mg} / \mathrm{m}^{3}$, respectively). The most polluted areas were the Railway and October districts, and the most common aerogenic pollutants were $\mathrm{SO}_{2}, \mathrm{NH}_{3}, \mathrm{CO}$.

Studies conducted to analyze the degree of fluctuating asymmetry of tree species showed different degrees of sensitivity of species to the value of anthropogenic pressure of the environment. Thus, the assessment of the fluctuating asymmetry showed high stability of the maple to the pollutant environment (the level of asymmetry in the transport zone is 0.039 against $0.077-0.078$ in the silver birch and the fragrant poplar).

The study of 363 trees belonging to 16 species showed that only 4 species were characterized as healthy $(\mathrm{K}<1.5)$. The overall level of attenuation was 2.16 ("weakened tree stands"). In these studies, the hypothesis was confirmed that the maple trees are somewhat more resistant to anthropogenic effects on the habitat. So the tree state level of the ash-leaved maple (Acer negundo) is characterized as "healthy" $(\mathrm{K}=1.40)$, and the maple species (Acer Platanoides), although characterized as "weakened", has the relatively low level of attenuation relative to other species $(\mathrm{K}=1.99)$. Cultivated plants were characterized by the least resistance to adverse factors: the assessment of the state 
of apple tree plantings (Malus domestica) showed a maximum level of attenuation -2.81 .

The high level of anthropogenic pollution in the transport zones of the city adversely affected roadside biotopes. It has been proved that roadside phytocenoses are largely sparse, the population density drops sharply (by 50-100\%), compared to cleaner functional areas, including residential ones, whose phytocenoses undergo trampling and periodic mowing. The plants of the transport zones are characterized by smaller linear sizes, both of shoots and leaves. The greatest negative impact of environmental pollution is on the total generative characteristics of plants, which leads to a decrease in reproductive qualities, reflected in a decrease in total seed productivity and deterioration in the quality of plant pollen.

The results of lichen indication showed that in the majority of the sites studied, the atmospheric air was highly polluted (pollution class 1 ), the concentration of $\mathrm{SO}_{2}$, was $0.10-0.30 \mathrm{mg} / \mathrm{m}^{3}$. The degree of projective cover of trees by lichens in these biotopes did not exceed 5.7-15.7\%, which is characterized as "lichen desert", and the biotic index ranged from 1.5 to 1.9 .

The studies have led to the conclusion about the rather unfavorable situation in the city of Ryazan and about the significant effect of aerogenic pollution on urban ecosystems.

\section{References}

1. G.Kh. Biktasheva, The main priority pollutants of the atmosphere of cities ISHIMBAI, Sterlitamak, Salavat Ural Ecolog. Bull. 2, 31-35 (2016)

2. E.S. Ivanov, E.A. Gladkova, A.M. Tsurgan et al., Assessment of the quality of the atmospheric air surface layer of the recreational zones of Ryazan and the territories of agricultural lands adjoining it with the help of lichens Agrar. Russia 3, 15-18 (2012)

3. A.I. Novak, Motor transport is the main source of air pollution in large cities in Coll. of sci. works of students of Ryazan State Agrotechnological Univer. named after P.A. Kostychev. Mater. of the sci.-pract. Conf. "Innovative directions and methods of realization of scientific research in the agroindustrial complex" 296-301 (2012)

4. Information about the state of the environment in the city of Ryazan, Administration of the city of Ryazan Retrieved from: http://admrzn.ru/ gorodskaya-sreda/upravlenie-blagoustrojstva/ formatsiya-o-sostoyanii-okruzhayushej-sredy-vgorode-ryazani

5. MGSN 1.02-02 Standards and rules for the design of integrated improvement on the territory of the city of Moscow with changes of 19 August 2003, 11 July 2006 Retrieved from: http://lightonline.ru/ documents/lightnorms/MGSN_1_02_02.html

6. Methods of inventory of emissions of pollutants into the atmosphere for motor transport enterprises (by calculation) (MADI, Moscow, 1998)

7. A.I. Novak, Yu.O. Lyaschuk, Assessment of air pollution in Ryazan region in Coll. Mater. of X Int. sci. and pract. conf. "Days of Science" 8-13 (2014)

8. Ministry of Natural Resources and Ecology of Russia, State report "On the state and protection of the environment of the Russian Federation" Moscow Retrieved from: http://www.mnr.gov.ru/ regulatory/list.php?part=1101, free

9. Yu.O. Lyaschuk, A.I. Novak, Assessment of the environmental risk of air pollution in the Ryazan region as a result of the activities of enterprises of the agro-industrial complex Herald of Tambov Univer. Ser. Natural and Techn. Sci. 19(5), 1700 1703 (2014)

10. A.B. Savinov, Phenotypic indication of plants under the conditions of technogenesis. Environmental Monitoring Part 5, 300-323 (NNSU Publishing House, Nizhniy Novgorod, 2003)

11. O.P. Melekhova, E.I. Egorova, T.I. Evseeva et al., Biological control of the environment: bioindication and bio-testing (Akademiya, Moscow, 2007)

12. L.M. Zakharov, Algorithm for managing the monitoring of pollutants in the system atmospheric air - soil - water - crop production - livestock products Herald of Ryazan State Agrotechnol. Univer. 3(35), 19-23 (2017)

13. E.V. Sokolskaya, B.I. Kochurov, Yu.A. Dolgov, V.A. Lobkovskiy, Multi-factor model as a basis for managing the environmental quality of urbanized territories Theoret. and Applied Ecology 2, 26-34 (2018)

14. Guidelines for calculating emissions of harmful substances by road (Gidrometizdat, Moscow, 1985) Retrieved from: https://znaytovar.ru/gost/2/ Metodicheskie_ukazaniyaMetodic5.html 1 